\title{
High Prevalence of Alpha- and Beta-Thalassemia in the Kadazandusuns in East Malaysia: Challenges in Providing Effective Health Care for an Indigenous Group
}

\author{
Jin-Ai Mary Anne Tan, ${ }^{1}$ Ping-Chin Lee, ${ }^{2}$ Yong-Chui Wee, ${ }^{1}$ Kim-Lian Tan, ${ }^{1}$ \\ Noor Fadzlin Mahali, ${ }^{1}$ Elizabeth George, ${ }^{3}$ and Kek-Heng Chua ${ }^{1}$ \\ ${ }^{1}$ Department of Molecular Medicine, Faculty of Medicine, University of Malaya, Kuala Lumpur 50603, Malaysia \\ ${ }^{2}$ School of Science and Technology, University of Malaysia-Sabah, Kota Kinabalu, Sabah 88999, Malaysia \\ ${ }^{3}$ Department of Pathology, Faculty of Medicine and Health Sciences, University Malaysia, Putra Serdang, Selangor 43400, Malaysia
}

Correspondence should be addressed to Jin-Ai Mary Anne Tan, maryanne@um.edu.my

Received 26 April 2010; Revised 30 June 2010; Accepted 20 July 2010

Academic Editor: Peter J. Oefner

Copyright ( 2010 Jin-Ai Mary Anne Tan et al. This is an open access article distributed under the Creative Commons Attribution License, which permits unrestricted use, distribution, and reproduction in any medium, provided the original work is properly cited.

\begin{abstract}
Thalassemia can lead to severe transfusion-dependent anemia, and it is the most common genetic disorder in Malaysia. This paper aims to determine the prevalence of thalassemia in the Kadazandusuns, the largest indigenous group in Sabah, East Malaysia. $\alpha$ and $\beta$-thalassemia were confirmed in $33.6 \%$ and $12.8 \%$, of the individuals studied respectively. The high prevalence of $\alpha$ - and $\beta$-thalassemia in the Kadazandusuns indicates that thalassemia screening, genetic counseling, and prenatal diagnosis should be included as part of their healthcare system. This preliminary paper serves as a baseline for further investigations into the health and genetic defects of the major indigenous population in Sabah, East Malaysia.
\end{abstract}

\section{Introduction}

Malaysia has a multiracial population of 28.3 million, consisting of $65.1 \%$ Malays and other Bumiputera groups: $26 \%$ Chinese, $7.7 \%$ Indians, and $1.2 \%$ of other ethnic groups (Population and Housing Census, 2000). The "Orang Asli" or the indigenous population in Malaysia are descendents of the Austronesian people and they form only $0.6 \%$ of the total population [1]. In West Malaysia, they have been officially classified into three main categories-Proto-Malay (Aboriginal-Malay), Negrito and, Senoi [1]. East Malaysia has the largest number of indigenous groups which make up to $60 \%$ of Sabah's and $50 \%$ of Sarawak's population. The indigenous groups have mainly lived as agricultural and fishing communities, but many have now integrated into urban communities and hold important administrative and academic positions.

The thalassemias are autosomal recessive disorders which result in reduced production of one or more of the subunits of hemoglobin. Thalassemia is a public health problem in
Malaysia and about $4.5 \%$ of the Malays and Chinese are $\beta$-thalassemia carriers [2]. Beta-thalassemia major produces severe anemia that requires life-long blood transfusions for survival. The molecular defects producing $\beta$-thalassemia are heterogeneous, and each ethnic group possesses its own specific set of mutations [3, 4]. Alpha-thalassemia has also been reported and the fatal condition, $\mathrm{Hb}$ Bart's hydrops fetalis, is present mainly in the Malaysian Chinese. The Malays possess the single $\alpha$-globin gene deletion that produces an asymptomatic disorder [5]. Thalassemia has rarely been observed in the Malaysian Indians who are migrants mainly from Southern India.

Although thalassemia is the most common genetic disorder in Malaysia, there is very little information regarding the presence of thalassemia in the indigenous population. A previous study showed that the Filipino $\beta$-thalassemia deletion which involves deletion of the entire $\beta$-globin gene was the only mutation in $20 \beta$-thalassemia major families from the indigenous communities in Sabah, East Malaysia [6]. Detailed molecular characterization of mutations that 
cause thalassemia in the Malaysian indigenous populations is limited, as studies have focused mainly on the major ethnic groups-Malays, Chinese and Indians. The aim of this molecular study is to detect the prevalence and types of $\alpha$ - and $\beta$-thalassemia in the Kadazandusuns, the largest indigenous group in Sabah. Information on the prevalence and spectrum of thalassemia defects will allow for effective genetic counseling and prenatal diagnosis of thalassemia in the Kadazandusuns in Sabah.

\section{Materials and Methods}

A total of 125 blood samples were obtained with informed consent from unrelated Kadazandusuns in Sabah in 2008. Genomic DNA was obtained using conventional phenolchloroform extraction. Routine hematology analysis including blood films for morphology was not done on the blood samples as they were collected from the interior and only reached the laboratory within 7 to 10 days of sample collection. In a recent study, we demonstrated that there was a progressive rise of the MCV from day 1 of storage [7]. High performance liquid chromatography (HPLC) to quantify hemoglobin subtypes in the blood samples for the presumptive diagnosis of thalassemia was also not possible as HPLC has to be carried out within 7 days of collection of blood samples stored at $4^{\circ} \mathrm{C}$.

2.1. DNA Amplification of the $\alpha$-Globin Gene. Deletional $\alpha$-thalassemia-Southeast Asian deletion (--SEA); rightward $-\alpha^{3.7}$ and leftward $-\alpha^{4.2}$ deletions were confirmed using a modified multiplex PCR [8]. The Filipino (-- ${ }^{\mathrm{FIL}}$ ) and Thai (-- $\left.{ }^{\text {THAI }}\right) \alpha$-thalassemia deletions were determined using separate assays [9]. The Filipino-specific deletion was amplified as a 597-bp fragment and the Thai-specific deletion as a 480-bp fragment. Amplification of the normal alleles for both deletions was simultaneously amplified in the same PCR reactions for each deletion. Amplification of the Mediterranean (--MED) $\alpha$-thalassemia deletion was not carried out in this study as this deletion has not been reported in Malaysia.

In addition, two nondeletional $\alpha$-thalassemias, $\mathrm{Hb}$ Constant Spring (HbCS) and $\mathrm{Hb}$ Quong Sze (HbQS), reported in Malaysian Malays and Chinese were also determined using an in-house developed Combine-Amplification Refractory Mutation System [10]. All PCR products were electrophoresed on ethidium bromide-stained agarose gels followed by analysis.

2.2. Molecular Characterization of $\beta$-Thalassemia. To determine the presence of $\beta$-thalassemia in the Kadazandusuns, the Filipino $\beta$-thalassemia deletion was screened first as this mutation was observed in a fairly high frequency in the indigenous communities in Sabah $[6,11]$. The primers, PCR mixture and PCR condition as described by Waye et al. [12], were used for the detection of the normal and the Filipino $\beta$-thalassemia deletion-specific sequence in this study.
Twenty-two common and rare $\beta$-globin gene mutations confirmed in Malaysians were determined in the Kadazandusuns using an in-house developed reverse dot blot system. The 22 mutations characterized are listed in Table 1. The reverse dot blot used to characterize the $\beta$-globin gene defects was a modification of previously reported protocols $[13,14]$. Briefly, specifically designed amino-modified oligonucleotide probes were applied to negatively-charged nylon membranes (Biodyne C Membrane, Pall USA). Betaglobin gene sequences in DNA from the Kadazandusuns were amplified in a multiplex PCR using DIG-labeled oligonucleotide primers. Amplified DNA was hybridized with the membrane strips at $42^{\circ} \mathrm{C}$ overnight. Membranes were washed with $0.5 \mathrm{X} \mathrm{SSC} / 0.1 \%$ SDS at $42^{\circ} \mathrm{C}$ for 30 minutes followed by a second wash with $2 \mathrm{X}$ SSC/0.1\% SDS at room temperature, for 15 minutes. Detection was carried out using anti-Digoxigenin-Alkaline Phosphatase conjugate (Roche, Germany) followed by colour development using Nitro blue tetrazolium chloride/5-Bromo-4chloro-3-indolyl phosphate toluidine salt (Roche, Germany).

\section{Results and Discussion}

Results from the molecular characterization of $\alpha$ - and $\beta$ thalassemia are presented in Table 1. Representative gel electrophoresis resulting from the Filipino $\beta$-thalassemia deletion in the $\beta$-globin gene is shown in Figure 1 . The results from this preliminary study showed that $16 / 125$ $(12.8 \%)$ of the Kadazandusuns possessed the Filipino $\beta$ thalassemia deletion in the $\beta$-globin gene. This indicates a fairly high presence of $\beta$-thalassemia in the Kadazandusuns. The Filipino $\beta$-thalassemia deletion has been reported in a Filipino family, in two Australian families of Filipino descent, and in an Indonesian family of Malay descent [1517]. The Filipino $\beta$-thalassemia deletion was first reported as a $45-\mathrm{kb}$ deleted sequence in the $\beta$-globin gene [16]. However, subsequent investigations of the end points of the defect confirmed a $118.5-\mathrm{kb}$ deleted sequence [12]. The deletion was also detected in 6/20 (30\%) of mutant alleles in the Makasarese people from Celebes (East Indonesia) [18]. In another study of 2954 healthy Filipinos in Taiwan, the deletion was confirmed in $45.8 \%$ of the $\beta$-globin gene mutant alleles [19]. Filipino $\beta$-thalassemia deletion is not present in the Malaysian Malays and Chinese [11], and appears to be specific only to the indigenous communities in East Malaysia. Twenty-two other $\beta$-globin gene mutations previously reported in the Malaysian Malay, Chinese, and Indian racial groups were absent in the Kadazandusuns studied.

Alpha-thalassemia was also detected in the Kadazandusuns (Figure 2) as the single $\alpha$-globin gene deletion $\left(-\alpha^{3.7}\right)$ was confirmed in $33.6 \%(42 / 125)$ of the individuals. Heterozygosity for the deletion $\left(-\alpha^{3.7} / \alpha \alpha\right)$ was confirmed in $27.2 \%(34 / 125)$ and homozygosity $\left(-\alpha^{3.7} /-\alpha^{3.7}\right)$ in $6.4 \%$ $(8 / 125)$ of the Kadazandusuns. The presence of the $-\alpha^{3.7}$ deletion is high in the Kadazandusuns when compared with the other racial groups. Previous studies showed that only $10.7 \%$ of Malaysian Malays, $10 \%$ of Chinese, and $7.4 \%$ of 
TABle 1: Frequency of $\alpha$ - and $\beta$-thalassemia defects in the Kadazandusuns in Sabah.

\begin{tabular}{lccccccccc}
\hline & \multicolumn{3}{c}{ Deletional $\alpha$-thalassemia } & \multicolumn{2}{c}{ Nondeletional $\alpha$-thalassemia } & \multicolumn{2}{c}{$\beta$-thalassemia } \\
& $-\alpha^{3.7}$ & $-\alpha^{4.2}$ & -- SEA & --FIL & -- THAI & HbCS & HbQS & Filipino $\beta$-thalassemia deletion $* 22 \beta$-mutations \\
\hline $\begin{array}{l}\text { Kadazandusun } \\
42\end{array}$ & 0 & 0 & 0 & 0 & 0 & 0 & 16 \\
$n=125(\%)$ & $(33.6 \%)$ & & & & & & & $(12.8 \%)$ \\
\hline
\end{tabular}

${ }^{*}$ The $22 \beta$-thalassemia mutations are CD41/42 (-CTTT), IVS2-654 $(\mathrm{C} \rightarrow \mathrm{T}), \mathrm{CD} 26(\underline{\mathrm{GAG}} \rightarrow \underline{\mathrm{AAG}}, \mathrm{HBE}), \mathrm{IVS} 1-5(\mathrm{G} \rightarrow \mathrm{C}),-28(\mathrm{~A} \rightarrow \mathrm{G}), \mathrm{CD} 43(\underline{\mathrm{GAG}} \rightarrow \underline{\mathrm{TAG}})$, $\mathrm{CD} 27 / 28(+\mathrm{C}),-29(\mathrm{~A} \rightarrow \mathrm{G}), \mathrm{CD} 71 / 72(+\mathrm{A}), \mathrm{CD} 17(\mathrm{AAG} \rightarrow \mathrm{TAG}), \mathrm{CD} 19(\mathrm{AAC} \rightarrow \mathrm{AGC})$, Poly A (AATAAA $\rightarrow$ AATAGA), $-88(\mathrm{C} \rightarrow \mathrm{T})$, Initiation codon $(\mathrm{ATG} \rightarrow \mathrm{AGG}), \mathrm{CAP}(+1)(\mathrm{A} \rightarrow \mathrm{C}), \mathrm{CD} 8 / 9(+\mathrm{G}), \mathrm{CD} 16(-\mathrm{C}), \mathrm{CD} 35(-\mathrm{C}), \mathrm{IVS} 2-1(\mathrm{G} \rightarrow \mathrm{A}), \mathrm{IVS} 1-1(\mathrm{G} \rightarrow \mathrm{A}), \mathrm{IVS} 1-1(\mathrm{G} \rightarrow \mathrm{T})$ and CD15 $(\mathrm{TGG} \rightarrow \mathrm{TA} G)$.

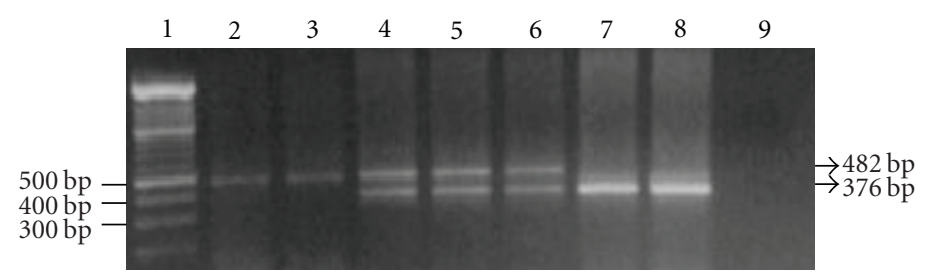

Figure 1: Detection of the Filipino $\beta$-thalassemia deletion on agarose gel after PCR. Lane 1: 100 bp molecular weight marker; lanes 2-3: normal controls with a 482-bp band; lanes 4-6: $\beta$-thalassemia carriers with the Filipino $\beta$-thalassemia deletion indicated by amplification of a 482 bp normal and a 376-bp deletion specific bands; lanes 7-8: $\beta$-thalassemia major with the Filipino $\beta$-thalassemia deletion indicated by amplification of a 376-bp band; lane 9: DNA blank.

Indians possessed this deletion [5]. The single gene $-\alpha^{3.7}$ deletion has a worldwide distribution [20] and is most dominant in African, Mediterranean, and Asian populations [21]. The two nondeletional $\alpha$-thalassemia studied, HbCS and $\mathrm{HbQS}$, were absent in the 125 Kadazandusuns samples. In a previous study in another indigenous group, HbCS was reportedly present in the Dayaks in Sarawak [22]. The Filipino (--FIL) and Thai (-- THAI) $\alpha$-thalassemia deletions were absent in the Kadazandusuns. The Southeast Asian (--SEA $) \alpha$-thalassemia deletion reported in Malaysian Chinese and Malays was also absent in the Kadazandusuns. This confirms that thalassemia mutations are not only specific to different populations, but can also differ in frequency between racial and indigenous groups within the same population.

The indigenous population which comprise 40 ethnic groups make up about $60 \%$ of the estimated 2.6 million people in Sabah [23]. They speak more than 50 languages and 80 dialects, and occupy specific geographical areas. The indigenous population is thus not a homogenous group, as it differs in physical characteristics, languages, life styles, social organizations, and religions. The Kadazandusuns are the most dominant and largest group and are mainly farmers, but with progress in their social economic status, they are now also employed as administrators, traders and modern farmers.

Results from this study indicate that the $118.5-\mathrm{kb}$ Filipino $\beta$-thalassemia deletion and the single $\alpha$-globin gene deletion $\left(-\alpha^{3.7}\right)$ are highly prevalent in the Kadazandusuns that inhabit the northern coastal plains and the mountain interiors of Sabah. Our sampling was from remote villages in Sonsogan Magandai, Sungai Magandai, Nalapak Pitas, and Panaitan. These are mainly impoverished villages that some are inaccessible by proper roads and do not have electricity or piped water supply. The health of the community is attended

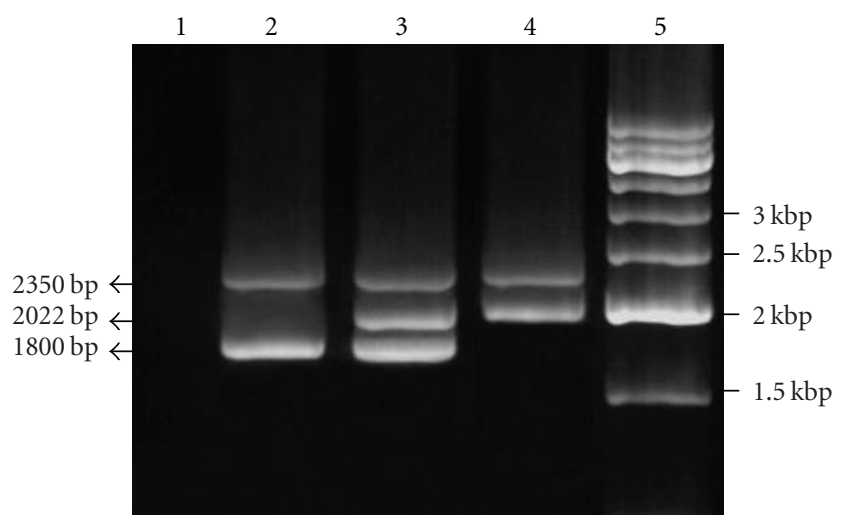

FIGURE 2: Detection of alpha-thalassemia on agarose gel after multiplex PCR. Lane 1: DNA blank; lane 2: normal controls $(\alpha \alpha / \alpha \alpha)$ with a $2350 \mathrm{bp} \mathrm{LIS}$ internal control band and a 1800 bp $\alpha 2$-globin gene band; lane 3: single $\alpha$-globin gene deletion carrier $\left(-\alpha^{3.7} / \alpha \alpha\right)$ with an internal control band, a 2022 bp deletion-specific band and an $\alpha 2$-globin gene band; lane 4: individual homozygous for $\alpha$ globin gene deletion $\left(-\alpha^{3.7} /-\alpha^{3.7}\right)$ with an internal control band and a $2022 \mathrm{bp}$ deletion-specific band; lane 5:500 bp molecular weight marker.

to by occasional flying doctors via helicopter service. Serious health problems are treated at the district hospitals and the individuals travel 5-6 hours by boats or public vehicles which cost 50-60 RM for a single journey. However, many resist seeking medical care as they are unable to pay for the transportation fare, because most families have unstable incomes and earn an average of 350 RM per month.

Carriers of $\alpha$ - and $\beta$-thalassemia are asymptomatic thus the affected individuals go through life unaware of their carrier status. Screening for thalassemia is not carried out on a routine basis on the Malaysian indigenous population. The 
Kadazandusuns frequently marry within their own group; thus, the risk of producing $\beta$-thalassemia major children is high since $12.8 \%$ of the Kadazandusuns studied possess Filipino $\beta$-thalassemia deletion.

In conclusion, the results from this study will serve as a baseline for further investigations into the genetic defects, and to provide better health services for the indigenous population in Malaysia. The DNA samples collected in this study were strictly selected from pure Kadazandusuns with no intermarriages with other ethnic groups for at least three generations. As the prevalence of both $\alpha$ - and $\beta$-thalassemia is relatively high in the Kadazandusuns, thalassemia screening should be quickly incorporated as a routine part of their healthcare system in order to identify asymptomatic carriers. The challenges to the implementation of more effective health care will include educating the Kadazandusuns about thalassemia as an inheritable disorder and, thus, the possibility of producing severely affected children. Genetic counseling and prenatal diagnosis have to be made available to husbands and wives who are carriers so that pregnancies with $\beta$-thalassemia major children are identified early and informed choices can be made with regards to continuation or termination of pregnancies. Management of children with $\beta$-thalassemia major should include availability of monthly blood transfusions and provision of iron chelation therapies to prevent death due to iron overload. Results and data derived from this study will be submitted to the Department for Orang Asli Affairs responsible for medical and health services for the indigenous populations in Malaysia. Specific programs relating to thalassemia screening and health care at the district hospitals for the indigenous populations will be proposed. Effective changes must be incorporated as the majority of the indigenous population in Malaysia are still unaware of their thalassemia status.

\section{Acknowledgments}

The authors gratefully acknowledge support from the Fundamental Research Grant Scheme (FRGS) IPTA no. FP025-2010A, University of Malaya's Research University Grant Scheme SF024/2007A, Postgraduate Research Fund PS229/2010A, and Science Fund 02-01-03-SF0403.

\section{References}

[1] Population Census JHEOA, 2004, "Department of Orang Asli Affairs (Jabatan Hal Ehwal Orang Asli, JHEOA)," February 2010, http://www.jheoa.gov.my/home.

[2] E. George, "Thalassemia: a public health problem in Malaysia," in Thalassemia Carrier Diagnosis in Malaysia, E. George, Ed., pp. 1-6, SP-Muda Printing Sdn Bhd, Kuala Lumpur, Malaysia, 1998.

[3] S. H. Orkin and H. H. Kazazian Jr., "The mutation and polymorphism of the human beta-globin gene and its surrounding DNA," Annual Review of Genetics, vol. 18, pp. 131-171, 1984.

[4] J. A. M. A. Tan, P. S. Chin, Y. C. Wong, K. L. Tan, L. L. Chan, and E. George, "Characterisation and confirmation of rare beta-thalassaemia mutations in the Malay, Chinese and Indian ethnic groups in Malaysia," Pathology, vol. 38, no. 5, pp. 437441, 2006.
[5] Y.-C. Wee, K.-L. Tan, T. W.-P. Chow, S.-F. Yap, and J.-A. M. A. Tan, "Heterogeneity in $\alpha$-thalassemia interactions in Malays, Chinese and Indians in Malaysia," Journal of Obstetrics and Gynaecology Research, vol. 31, no. 6, pp. 540-546, 2005.

[6] M. K. Thong, Z. Rudzki, J. Hall, J. A. Tan, L. L. Chan, and S. F. Yap, "A single, large deletion accounts for all the betaglobin gene mutations in twenty families from Sabah (North Borneo), Malaysia," Human Mutation, vol. 13, no. 5, pp. 413415, 1999.

[7] E. George, S. K. Khoo, A. B. Mokhtar, and U. Nur Aini, "Screening for thalassemia in pregnant women: a laboratory perspective," Malaysian Journal of Medicine \& Health Sciences, vol. 1, pp. 111-117, 2005.

[8] S. S. Chong, C. D. Boehm, D. R. Higgs, and G. R. Cutting, "Single-tube multiplex-PCR screen for common deletional determinants of $\alpha$-thalassemia," Blood, vol. 95, no. 1, pp. 360362, 2000.

[9] B. Eng, M. Patterson, S. Borys, D. H. K. Chui, and J. S. Waye, "PCR-based diagnosis of the Filipino (_ _ FIL) and Thai (- _ THAI) $\alpha$ - thalassemia-1 deletions," American Journal of Hematology, vol. 63, no. 1, pp. 54-56, 2000.

[10] Y. C. Wee, K. L. Tan, K. H. Chua, E. George, and J. A. M. A. Tan, "Molecular characterization of Hemoglobin Constant Spring and Hemoglobin Quong Sze by Combine-Amplification Refractory Mutation System," Malaysian Journal of Medical Sciences, vol. 16, pp. 23-30, 2009.

[11] J. A. M. A. Tan, E. George, K. L. Tan et al., "Molecular defects in the $\beta$-globin gene identified in different ethnic groups/populations during prenatal diagnosis for $\beta$ thalassemia: a Malaysian experience," Clinical and Experimental Medicine, vol. 4, no. 3, pp. 142-147, 2004.

[12] J. S. Waye, B. Eng, J. A. Hunt, and D. H. K. Chui, "Filipino $\beta$-thalassemia due to a large deletion: identification of the deletion endpoints and polymerase chain reaction (PCR)based diagnosis," Human Genetics, vol. 94, no. 5, pp. 530-532, 1994.

[13] F. F. Chehab, J. Wall, and S. P. Cai, "Analysis of PCR products by covalent reverse dot blot hybridization," in PCR Strategies, M. A. Innis, D. H. Gelfand, and J. J. Sninsky, Eds., pp. 130-138, Academic Press, 1995.

[14] P. Winichagoon, V. Saechan, R. Sripanich et al., "Prenatal diagnosis of $\beta$-thalassaemia by reverse dot-blot hybridization," Prenatal Diagnosis, vol. 19, no. 5, pp. 428-435, 1999.

[15] B. Eng, D. H. K. Chui, J. Saunderson, N. F. Olivieri, and J. S. Waye, "Identification of two novel beta zero-thalassemia mutations in a Filipino family: frameshift codon 67 (-TG) and a beta-globin gene deletion," Human Mutation, vol. 2, no. 5, pp. 375-379, 1993.

[16] P. I. Motum, A. Kearney, T. J. Hamilton, and R. J. Trent, "Filipino $\beta 0$ thalassaemia: a high $\mathrm{Hb}$ A2 $\beta 0$ thalassaemia resulting from a large deletion of the 5' $\beta$ globin gene region," Journal of Medical Genetics, vol. 30, no. 3, pp. 240-244, 1993.

[17] A. J. Dimovski, E. Baysal, D. G. Efremov et al., "A large $\beta$ thalassemia deletion in a family of Indonesian-Malay descent," Hemoglobin, vol. 20, no. 4, pp. 377-392, 1996.

[18] I. Setianingsih, "Molecular basis of $\beta$-thalassemia in indonesia: application to prenatal diagnosis," Molecular Diagnosis, vol. 3, no. 1, pp. 11-20, 1998.

[19] T.-M. Ko, A. P. Caviles Jr., H.-L. Hwa, C.-W. Liu, P.-M. Hsu, and Y.-P. Chung, "Prevalence and molecular characterization of $\beta$-thalassemia in Filipinos," Annals of Hematology, vol. 77, no. 6, pp. 257-260, 1998. 
[20] E. Baysal and T. H. J. Huisman, "Detection of common deletional $\alpha$-thalassemia-2 determinants by PCR," American Journal of Hematology, vol. 46, no. 3, pp. 208-213, 1994.

[21] D. Weatherall and J. B. Clegg, The Thalassemia Syndromes, Blackwell Science, 4th edition, 2001.

[22] J. Ganesan, L. E. Lie-Injo, and B. P. Ong, "Abnormal hemoglobins, glucose 6 phosphate dehydrogenase deficiency and hereditary ovalocytosis in the Dayaks of Sarawak," Human Heredity, vol. 25, no. 4, pp. 258-262, 1975.

[23] Population and Housing Census, 2000, "Population Distribution and Basic Demographic Characteristics Report," Department of Statistics Malaysia, 2004, http://www .statistics.gov.my. 

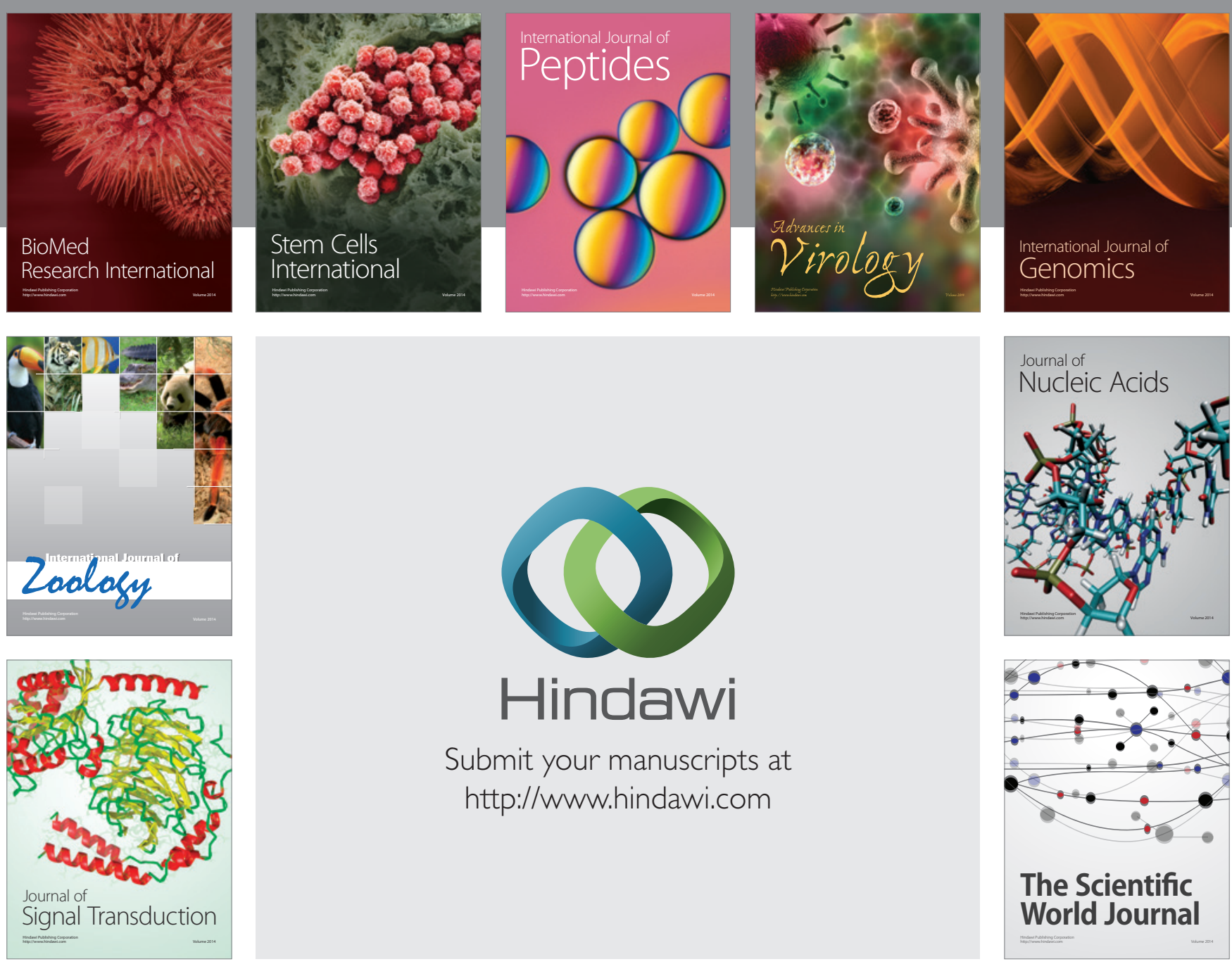

Submit your manuscripts at

http://www.hindawi.com
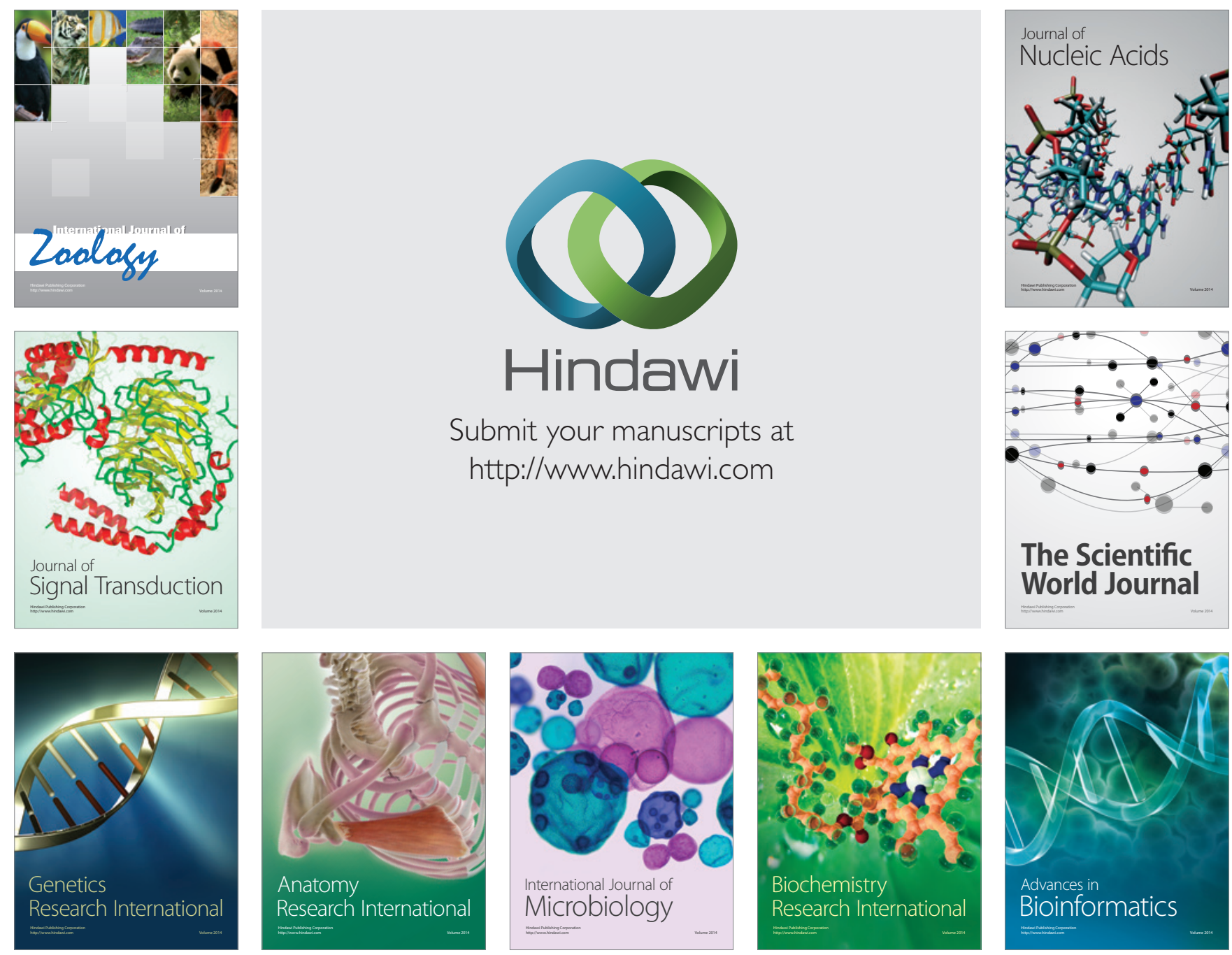

The Scientific World Journal
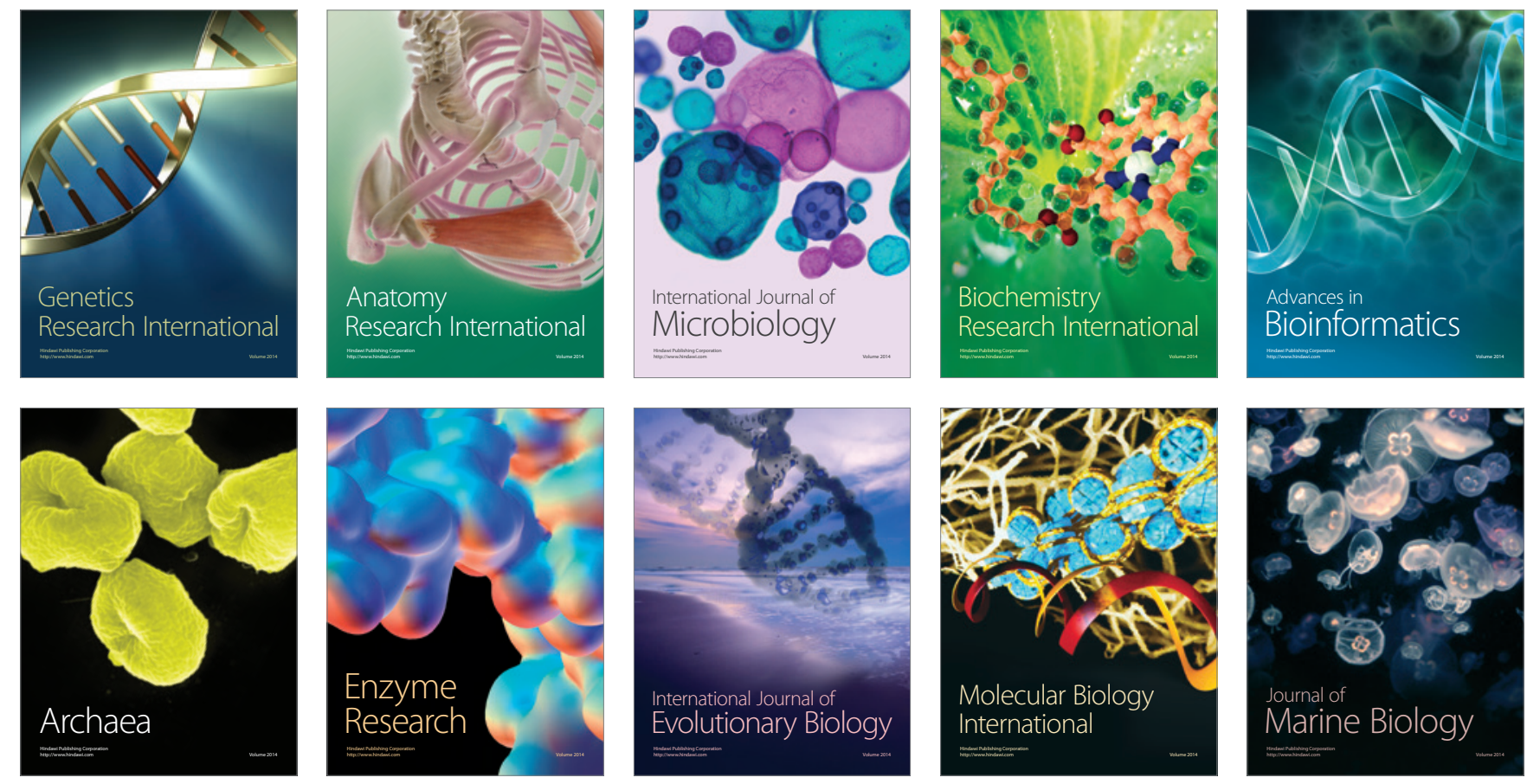